\title{
Viral Hauntology: Specters of AIDS in Infrastructures of Gay Sexual Sociability
}

KRISTIAN MØLLER \& CHASE LEDIN

\section{INTRODUCTION}

In recent years, HIV treatment has become so effective that a patients' viral load can become so low that it is undetectable, which in turn reduces the risk of viral transmission to zero (Eisinger, Dieffenbach, \& Fauci 2019). At the same time, for people who are HIV negative, the use of the medical regimen "pre-exposure prophylaxis," or "PrEP," reduces the risk of HIV infection by $92 \%-99 \%$ (Anderson et al. 2012). The PrEP regimen typically targets people at high risk of HIV infection and consists of taking HIV medicines either daily or through event-based dosing ("PrEP" 2019). These innovations are celebrated as key in the fight against AIDS, and rightfully so. They offer hope to affected populations, that they might engage with the AIDS epidemic in a way that is more commemorative than somatically threatening. Thus, modern HIV medication promises access to a gay subjectivity that expands notions of sustainability otherwise made unavailable by the AIDS crisis. This access potentially alleviates stigma and enables a reorientation of mostly gay male sociability and politics across and beyond the viral serostatuses of "HIV negative" and "HIV positive."

Such medical innovation does not erase the trauma of the AIDS crisis. Such trauma continually impacts gay cultures today, in the minds and on the bodies of survivors, and more broadly by informing how gay commu- 
nities imagine gay sexual sociability to be virtuous, sustainable, transgressive, dangerous, etc. Contemporary gay sexual sociability is informed by the socio-technical interventions of condom use, regular STI testing, and sexual serosorting, practices that were negotiated during and after the AIDS crisis in order to retain access to gay somatic pleasures. These practices of vitality are not individual endeavors but rather socially negotiated responses, put in place and governed through an ethic of collective, cultural sustainability (Rofes 1998).

The biomedical potential of this medical regimen, in the same way antiretroviral therapy (ART) made HIV positivity a manageable chronic condition, should and does invite hope. But the fact remains that while attitudes seem to be changing, there is a persistence of wariness and negative responses to the emergence of sexual cultures informed by the affective affordances of PrEP. These affective orientations do not align with the phantasmagoric futures that PrEP makes available; rather, they seem to reinstall modes of relationality based on fear of HIV. It is this persistence or "temporal drag" (Freeman 2010, 95) that this chapter concerns itself with. To further understand the relationship between the lingering fear of HIV and new prevention methods, it is necessary to interrogate how the HIV crisis materialises for gay people and their communities. Additionally, it is crucial to understand how affective sedimentations impact contemporary material and structural innovations that sustain, support, and change gay sexual sociability beyond and after the time/s of the crisis.

Drawing from queer theory (Freeman 2010) and HIV/AIDS sociology (Decoteau 2008; Gordon, 2008; Gill-Peterson, 2013; Petrus, 2019), we take hauntology (Derrida 2006) as a useful framework for a diachronic and synchronic analysis of how past and present materials and ideas affect and might affect those living "post crisis" (Race 2001; Kagan 2018), particularly when the effects of the AIDS crisis (for some) manifest as distant affective echoes. This chapter leans on Derrida's (2006) concept of "hauntology" to develop what we call a "viral hauntology" coterminous with the development of new HIV prevention methods. This affect-driven intervention closely examines how the affective economies of circulation, as described by Sara Ahmed (2004), are embedded in current material infrastructures of HIV prevention technologies. We argue that viral hauntology allows us to think deeply about how 'old' technologies and their social lives fold over and into new ones, and how the folding process 'drags' in order to imagine other, more inclusive, gay socio-sexual futures. 
In this chapter, we think about HIV/AIDS not only as a somatic condition affecting a body, but also as a socio-technical matter. With HIV/ AIDS's production of virality, certain norms and ideas about what constitutes "good" sexuality have emerged (Kagan 2018), norms that are then enforced, contested or modulated through the production and use of material infrastructures of gay sociability. Such materialist thinking is inspired by Kane Race's (2018) mobilization of Actor-Network-Theory, in which he considers how HIV/AIDS work on gay life through complex flows of chemical, digital, and communal infrastructures. Extending this research into the field of affect theory, we analyze two case studies to demonstrate how these infrastructures change through viral hauntology.

The two case studies are used to unpack how socio-technical responses to the HIV/AIDS crisis play a role in the cultural and interfacial responses to the availability of the PrEP regimen. In the first case study, we examine the 'PrEP whore' figuration. We look closely at the circulation of anti-PrEP and anti-promiscuity sentiments, and how the condom's materiality and historicity-as a 'preferred' safer-sex technology for men who have sex with men (MSM) - is intertwined in this particular discourse. In the second case study, we compare how the gay hookup apps Grindr and Scruff (two of the most influential digital platforms for contemporary gay sociability) frame discussions of safer-sex practices and HIV status. In the following section, we will detail a conceptual framework for thinking about what could be called the affective 'haunting' of these HIV-impacted infrastructures, and how certain feelings 'haunt' interpretations of the HIV virus, the minds of gay people, and central infrastructures of gay life.

\section{AFFECTIVE HAUNTINGS OF HIV}

In No Future (2004), Lee Edelman argues that speculating and hoping for a queer/er future is a tool of heteronormative reproduction. In response, José Esteban Muñoz (2009) argues that hopefulness can be used as a mode of queer orientation, to access and imagine "networks of commonality and the structures of feeling that link queers across different identity markers, including positive and negative antibody status as well as bodies separated along generational lines" (47). In place of focusing largely on the image of the child, Muñoz employs a ghost metaphor to imagine how queer pasts and futures might affect shared community building. Both scholars address the pressing belief that neoliberal culture is hegemonic and thus 
integrates any forms of queer response/s to social and cultural reform. As both Lauren Berlant (2006) and Sara Ahmed (2010) have noted, the affective investments needed to change these infrastructures are largely made impossible by the marketization of individual life under 21st-century capitalism. We follow from this line of inquiry to think about how the viral hauntology of HIV/AIDS is seated within contemporary forms of social life and the infrastructures of gay sociability. More specifically, we take from the affective and temporal threads within queer theory to understand how HIV fearfulness - in spite of the promises or "queer optimism" (Snediker 2008) of PrEP - continues to haunt gay subjectivity, albeit in new ways.

We suggest that Jacques Derrida's affective theory of hauntology (2006) is a helpful tool for understanding how past forms of HIV epistemologies linger through the use of PrEP. Cultural studies has a long history of utilizing hauntology as a way of understanding the social life, memorialization, and trauma of the AIDS epidemic (Decoteau 2008; Gordon 2008; Gill-Peterson 2013; Scott 2015; Petrus 2019). Hauntology describes the historical conditions producing "ends" or discourses about "the end" (Derrida 2006, 10). In other words, it is a tool for understanding the progress from and exchanges between one affective state (terror) and another (chronic well-being). We suggest that the use of PrEP operates within a hauntological register. Past forms of social life, memories, and trauma linger within contemporary material conditions of HIV/AIDS, thus opening the use of new prevention technologies to past forms of interpretation and critique. Hauntology directs our attention to the affective conditions that recur through the "epidemic of meanings and signification" (Treichler 1999, 1). Rather than approaching memories as rooted in traumatic experiences of HIV, always-already reinstalling memory-astrauma in the present, a hauntological approach specifies a "frequentation" or "visit" that can be either "friendly" or alternatively "signify strict inspection or violent search, consequent persecution, implacable concatenation" (Derrida 2006, 126). The specters of HIV/AIDS seek to make themselves felt within the historical (re)production of its signs and significations. Hauntology insists that the spectre of the 'AIDS past,' while clearly referencing ontological, epistemological and material forms of pastness, simultaneously appears as a creature of the present, or as Derrida (2006) puts it "...it begins by coming back" (11). While reflecting an image of the past, the ghost is not a history that repeats itself through trauma, but rather a co-temporal figuration that emerges alongside certain ideas 
of pastness in the present. For Derrida, a haunting does different kinds of work depending on its instantiation in language, the object it attaches itself to, or rather, is always already co-constituting. Derrida complements this agential haunting with a sort of paradoxical and affective starting/ ending point: a moment of mourning, as he calls it, that describes a wish to fix in time and place the ghostly presence within a material world that continues to change. In short, viral hauntology refers to and describes the spectral presence of history as a process of (un)fixing material presence to/from an imagined past.

Viral hauntology allows us to think about the mourning of the lives lost to AIDS as embedded in contemporary socio-material infrastructures. Understanding the use of PrEP within an affective economy - that is, the circulation of various forms of pastness and presentness that emerge through viral hauntology-allows us to look at the folds of affective economies within and across HIV epistemologies. This affective theory allows us to think about socio-technical innovations as becoming saturated with specific emotions through pendulum movements between the concrete and the abstract, between, for instance, the affective attachments to the condom, PrEP, or a hook-up app drop down menu, and the affective exchange that occurs when new intervention technologies emerge in response to HIV crisis and prevention. Critically, we argue that previous affective values might (re)attach to new prevention technologies and thus haunt their construction during the process of cultural signification and sociomedical interpretation.

\section{CASE STUDY 1: THE 'PREP WHORE’ AND THE VIRTUOUS CONTAINMENT OF SEMEN}

Within gay culture the hierarchy of bodies formed around HIV and its treatments are now disturbed by the biomedical realities that PrEP makes available. It invites the hope that fear does not need to be mobilized to the same degree in MSM sex, that HIV stigma will fall away, and that HIV itself will be a thing of the past. From a chemical infrastructural perspective, PrEP makes available a new body assemblage that in practice not only removes the risk of contracting HIV individually, but also on a population level has proved an effective intervention. While using PrEP then could be evaluated as 'good' and 'virtuous,' in response, the 'PrEP whore' figuration has emerged and gained significant traction. First registered in 
social media and hook-up app discourse of gay men in San Francisco in 2014 (Belluz 2014; Garcia 2014), the 'PrEP whore' label is used to shame men using PrEP, insisting "that those who use PrEP are somehow taking a prevention shortcut, a copout from the responsible use of condoms" (Spieldenner 2016, 1691). On gay hook-up apps, the rejection of people who take PrEP is part of a larger trend of negative public statements ("no-lists" see Albury, et al. 2017) that reject bodies and identities not conforming to a homonormative ideal embodied by white, HIV negative, conventionally attractive, gay, cisgender men.

The 'PrEP whore' belongs to a genealogy of "panic icons" like homosexuals, Haitians, heroin users, hemophiliacs (González 2019, 33); that is, "patient zero" figures that assert specific people, groups or practices are the root of the problem. Similar to panic-driven thinking, the rejection and shaming of PrEP users can be said to maintain heteronormative respectability politics (Kagan 2018, 134-135). Such politics have in the last couple of decades come to mark much of LGBTQ (especially gay) politics, leading Ahlm to describe the practice of negotiating sexual encounters on gay dating apps as one of "respectable promiscuity" (Ahlm 2017, 1). By tying the medical regimen in with the slut figure, PrEP's potential for sexual and psychological freedom from sickness and (fear of) death is marked as unethical, and the PrEP user as someone untrustworthy. As such, what we would term the 'PrEP whore' figuration, while by no means the most widespread discourse on the subject, also provides a concentrated glimpse into how fear, shame, and disgust are mobilized in what is perceived to be the ethical modulation of gay sexual sociability.

Further, PrEP is much more than the discourse of the PrEP whore. It is as an interface between gay histories of (anti)viral sociability, and visions of biomedicalized sexual futures. In their tracing of PrEP whore discourse, González (2019) evaluates PrEP's relationship to the binary of promiscuity and responsibility in the following way:

But there are many ways to make queer sex risky - in culturally positive as well as negative senses - after the spectre of HIV, personified in panic icons like the Truvada whore, is laid to rest. PrEP allows us to envision a future without AIDS: a vision that is truly revolutionary (González 2019, 47).

González imagines that PrEP will enable a time in which HIV/AIDS does not exist, virally or socially as a category that organizes gay sociability. While there is no denying that gay sex and futurity without the spectral presence of HIV/AIDS would open up new erotic spaces for sexual socia- 
bility, the language of "revolution" seems so invested in the eradication of the HIV virus, that the affective and social histories are willfully erased. Yet these histories are deeply meaningful for individuals to make sense of life with and without HIV. They are central to current forms of gay sociability and indeed subjectivity. So we should be careful to not discursively force such a future into existence. The drive to forget is fed by the promise of viral insignificance made by the hopeful PrEP user, but may in fact end up erasing the role of the HIV virus as an agent of social and sexual production. Thus we must remain attentive to the ways in which the affective sedimentations of HIV continue to pervade the production of gay spaces, sexualities, and sociabilities. In doing so, we seek to make intelligible the affective impact of material and structural innovations of HIV prevention beyond and after the time/s of the crisis.

One approach is to think about how PrEP disrupts the condom's dominance in gay sexual health practice. PrEP attracts attention not only to the evaluation of its effectiveness, but also becomes subject to ethical evaluation amongst potential users and non-using critics. This dual evaluation constructs its social value among its users and critics. We argue that this construction happens in part in dialogue with the condom and the social value it has accrued over time. More specifically, the power of the 'PrEP whore' figure to slut shame those using PrEP should be seen as stemming from a genealogy of safer-sex technologies for gay and bisexual men, in which the condom figures as the dominant technology. The social evaluation as well as the uptake of PrEP should be understood in relationship to the historical negotiation of prophylactic usage. The genealogy of PrEP has as its organizing principle the containment of semen. Materially, while it is the effect (not viral transfer) that is the function that properly describes the condom's use in HIV prevention, over time it is the very separation of fluids that becomes the object to which affective states of safety and responsibility stick and accumulate. It is the literal exchange of fluids that is made to feel corruptive, even if there is no viral presence within those fluids. Affectively, for those using the term 'PrEP whore' disparagingly, the condom retains the feeling of safety; it is a rigid sexual technology that is affectively and ontologically 'safe.' While this feeling of safety is based on its effectivity in reducing risk of HIV infection, we would argue that over time the condom loses affective intensity, a value that "haunts" PrEP by making insensitivity a sign of virtue. Following Mary Douglas' (1966) seminal analysis of rituals, pollution, and purification, the latex separa- 
tion of genitals and containment of fluids becomes the primary way that normative sexual practice and transgression emerge and diverge. Denying oneself the pleasure of fluids entering orifices, to instead keep semen in its 'proper' place inside the condom, becomes the vehicle of virtuous sex (see Spieldenner 2016 for a discussion of the "dirty/clean" dichotomy's role in PrEP whore discourse). It is this ethics of fluids that over time becomes unfixed from the condom as a technology, allowing fear of 'semen out of place' to travel through the social normativity of hook-up app discourse to haunt the PrEP regimen. In other words, the affective investments that have sedimented around condoms may break loose and re-orient their affective significance in order to reattach to PrEP and modulate its very social existence (Ahmed 2010). Thus, thinking of PrEP as haunted by both the practical and material ways the condom keeps its user from contracting or passing on HIV illuminates the affective attachments that accrue through prophylactic innovation.

In short, the very loss of sensation in condom use becomes entangled with the notions of respectability and responsibility. The modulation of sensation by the latex condom is made to feel, if not good, then at least right, creating an affective anchoring to the ethics of how safer sex should feel. This normative configuration of what counts as 'virtuous,' 'sensual' and 'right' induces temporal drag as it attaches itself to PrEP. The process creates a figuration (i.e. the 'PrEP whore') that operates within a new set of materialities, one that does "re-crisis" work (Kagan 2015) by re-applying an affective orientation from previous viral epistemologies. As we have argued, it is the affective investments in the separation of bodily fluids that travel and reattach in the affective economy of HIV prophylaxis and prevention, allowing the PrEP whore figure to circulate and work alongside the hopeful PrEP user. In the new medico-sexual reality of the late 2010s, nothing mandates a 'right' way (and thus social value) of using PrEP. Rather, multiple forms of 'right' emerge when we examine the affective sediments that attach to PrEP. Thus a new approach to thinking about the evolving relationship between condoms and PrEP is necessary in order to better understand how these conflicting discourses about PrEP use co-exist and inform the production of gay spaces, sexualities, and sociabilities. 


\section{CASE STUDY 2: GRINDR AND THE FANTASY OF HIV NEGATIVITY}

The importance of dating apps (or 'hook-up apps' as is the preferred term in queer media studies) to LGBTQ people's sexual sociability is well described (Mowlabocus 2010; Race 2015, Albury \& Byron 2016; Duguay, Burgess, \& Light 2017; Møller \& Nebeling Petersen 2017). Their affective and digital infrastructural characteristics are thus important when studying the social life of HIV. To understand viral hauntology within digital infrastructures, we compare the design of safer sex and HIV disclosure options in the apps "Grindr" and "Scruff" (see Figure 1). These two major queer hook-up app competitors offer different rhetorical resources with which the users can communicate their safer-sex practices and their viral status. Importantly, we look at the fantasy of HIV negativity as an affective sediment that occurs across digital infrastructures and critically informs gay sociability. We argue that this structuring of HIV negativity and chronic health constitutes a viral haunting of the hook-up app infrastructure.

Scruff and Grindr both serve as framing devices for sexual health negotiation, but in markedly different ways. In the profile editor, under the headline "sex," Scruff invites disclosure of "safety practices", which includes "condoms," "PrEP," and "treatment as prevention" (HIV prevention methods and programs that use antiretroviral treatment, ART) to decrease the risk of HIV transmission (for more see "Treatment" 2019). In doing so Scruff frames negotiations of sex and safety as a practice that the user might adopt. At first glance, the categories seem linked to serostatus. One user who believes they are HIV negative might choose "condoms" or "PrEP," and another user, a person living with HIV (PLWH), might choose "condoms" and "treatment as prevention." While the latter category seems to indicate that the adoptee is a PLWH, it might also be used by a person who believes themself to be HIV negative and seeking sex with men who use treatment as prevention. Thus, by focusing on practice, Scruff's design gently avoids supporting user expectations of serostatus disclosure. When Scruff prioritizes practice-disclosure over sero-disclosure, it materializes and enforces a specific historical tradition of serostatus "non-disclosure," that is a "traditional policy of assuming any of their casual partners could be HIV-positive" (Race 2010, 11). This tradition prescribes that all encounters should be thought of as 'risky.' In other words, prophylactic method, such as condom use, stands in for 


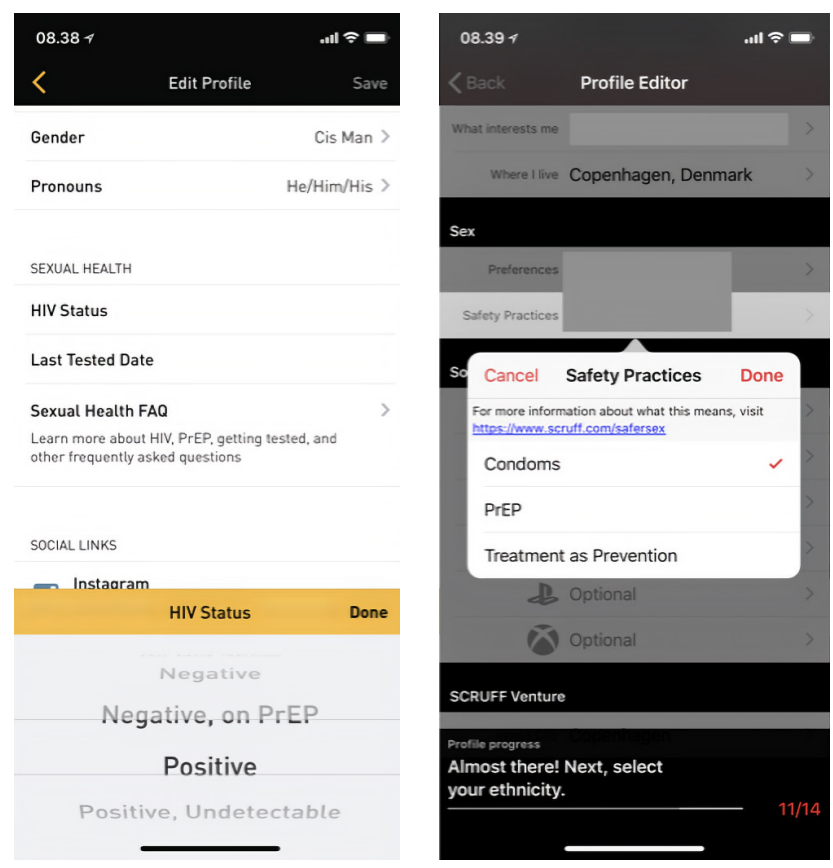

Figure 1. Disclosure options for "HIV status" in Grindr (left); and "safety practices" in Scruff (right).

verbal sero-disclosure and emphasizes practice-disclosure. By making HIV positivity a presumed serostatus, practice-disclosure seeks to enable sex, minimize further infection, and avoid HIV/AIDS stigmatization.

Conversely, under the heading "sexual health," Grindr asks the user to disclose "HIV status," and to choose between "Do Not Show," "Negative," "Negative, on PrEP," "Positive," and "Positive, Undetectable." The options combine the status of viral load in the body with any HIV medical regimes that minimize risks of viral transfer and seroconversion. ${ }^{1}$ Serostatus disclosure is thus privileged over safer sex practice. Kane Race (2010) documents that such categorial focus on HIV status disclosure, while technically presenting an equal opportunity for all, contributes to "a disabling and frustrating affective climate for HIV positive participants in gay sexual culture" (13). Going beyond the stigmatization of PLWH, which makes disclosure a moment of potentially intense anxiety, we point out that by offering the self-identification category "HIV negative" next to, for example, "positive," Grindr's design falsely imagines a 
cultural binary in which the non-seroconverted body is knowable in the same way as the seroconverted one. In doing so, the apparatus collapses these gay subjectivities into the "inevitability" of seroconversion (Román 1998, 226). Hence Grindr's infrastructure extrapolates the polarization of HIV subjectivities through the "unconscious," affective apparatus of "inevitable" transmission (Odets 1995; Román 1998). Put simply, Grindr as a digital infrastructure creates a social understanding that being HIV negative is something we can know and feel in the same way as HIV positivity. This makes the inclusion of "HIV negativity" a telling option because its knowability is presumed as a "stable" and "known" feeling, in other words, a bodily condition that can be imagined into existence through the interface design.

Avoiding speculation about designer knowledge and intentions, the fact that this interface design remains uncontested indicates to us how highly valued the negative body is among designers and its users. HIV negativity presents as a viable, obvious, and useful category because it coincides with a disclosure-practice that can be 'known.' To reflect further on what work the interface does to structure thinking about HIV virality and knowledge, we return to the framework of viral hauntology. Derrida's hauntology is as much about processes in the contemporary moment as it is about the past. The deliberate focus on HIV disclosure of Grindr can be seen as less the interface being haunted and more the interface chasing after the epistemological phantasmagoria of HIV negativity. Whether or not the designers are aware that the categories offered seem to forcefully insist that knowledge about sero-negativity is the way to have good, sustainable gay sex, is beside the point. The fact is that such a forceful push toward measuring HIV negativity alongside positivity is materialized and privileged in this digital infrastructure for global gay sociability.

To further unpack the affective sedimentation of this epistemological phantasmagoria, we consider Ahmed's (2004) exploration of affective ripples and the justifiable actions that emerge through the introduction of the "bogus asylum seeker." Ahmed writes:

It is always possible that we may not be able to tell, and that the bogus may pass their way into our community. Such a possibility commands us (our right, our will) to keep looking, and justifies our intrusion into the bodies of others (Ahmed 2004, 46). 
As the HIV negative body is a socially valued instance of the gay body, its very introduction and circulation as a disclosure-practice commands Grindr users to keep looking for it. Even though they will never be able to reliably identify HIV-negative bodies, the infrastructural organization of Grindr nevertheless extends the historical focus on HIV-positive bodies to HIV-negative ones. All things equal, this intensifies the serostatus inquiry and disclosure ethos that so readily reproduces HIV stigma. As such, previous viral discourses, such as "inevitable transmission," continue to operate as a "ghost-like figure" that sediments fear and dread through "an anticipation of a future injury" (Ahmed 2004, 46). The ability of the HIV-negative figure to produce new affective relations is thus not merely based in its materiality as a real 'thing,' but rather its immateriality and status/es become unfixed referents which accumulate and retain multiple HIV epistemologies across time.

\section{VIRAL HAUNTOLOGY AND HOPEFULNESS FOR AN AIDS-LESS FUTURE}

The chemical infrastructure of gay sexual sociability will change significantly with the normalization of PrEP use. As this chapter has shown, this biomedical innovation transforms unevenly within social infrastructures, such as the PrEP whore, and digital infrastructures, such as gay hook-up apps, and retains affective sediments from previous epistemological interpretations of HIV/AIDS. We have drawn upon Freeman's (2010) concept of temporal lag, Derrida's (2006) hauntology, and Ahmed's (2010) affective economies of circulation to draw out how the privileging of HIV negativity continues to be lodged in these socio-technical infrastructures which are central to contemporary gay sexual sociability. Their configurations of virality, the healthy body, and sustainable gay sexuality draw on affective registers that develop and accumulate across times of crisis and post-crisis.

Theoretically, this chapter shows that a viral hauntological approach allows for a socio-technical analysis of the HIV virus that cuts across diachronic and synchronic planes. Against this background, our analyses have brought out the ways feelings of sexual ethical virtue might be produced in relation to specific safer sex technologies, and how these normative orientations are translated across time and reattach to new technologies. Contemporary gay sex culture's investment in the non-se- 
roconverted body materializes in queer hook-up app disclosure options. This works as a device to re-frame HIV serostatus, with the purpose of creating sexual encounters seemingly free of HIV/AIDS history. Based on Freeman's analysis of contemporality as constituted by temporal lag, we are wary of considering this reframing of disclosure-practice as a "PrEP revolution." We argue that such a claim lends itself to a narrative bracketing of the histories of HIV/AIDS, which prematurely signifies the "end" of HIV/AIDS and eliminates the prevalence of HIV in the production of contemporary gay spaces, sexualities and sociabilities.

In unpacking the affective sedimentation within the PrEP whore figure, its role in contemporary gay culture should not be overstated. Much like the usefulness of homonormativity as a modus for queer critique has been questioned, with some scholars pointing to how it defaults to making ordinary gay life suspicious (Brown 2012), it should be noted that PrEP's configuration of what is and is not deemed ethical gay sexual sociability is not globally or even regionally uniform. Crucially, there are massive transnational differences in terms of the Global North having much higher adoption rates than the Global South. Further, PrEP is typically not equally available within a nation's population, with models of healthcare and national health politics significantly affecting the availability for low income and marginalized groups. Thus, the normative work that attaches itself to PrEP, with the PrEP whore figure being one of them, should always be considered in relation to material and local contexts.

Ultimately, as we have shown, the histories of AIDS crisis operate alongside contemporary 'post-crisis' infrastructures for gay sexual sociability. Viral hauntology continues to produce multiple ways of interpreting and analysing the significance of new prevention technologies, including the hopefulness for an AIDS-less future, which emerges through the image and use of PrEP; the intelligibility of the HIV seronegative body related to, and thus bound up with, the seropositive body; and the historical confidence in the 'safety' condom-use enables, by keeping bodily fluids separate. By focusing on the temporal lag of the AIDS crisis, and the proliferation of affective sedimentations it produces, we suggest that viral hauntology allows for critical attentiveness to how multiple discourses compose the significance and use of PrEP. Such an approach enables us to think deeply about how 'old' technologies and their social lives fold over and into new ones, and how the folding process "drags" in the process of imagining and negotiating new modes of gay sexual sociability. 


\section{NOTES}

1. Seroconversion is the time period during which a specific antibody develops and becomes detectable in the blood.

\section{REFERENCES}

Ahlm, J. (2017). Respectable Promiscuity: Digital Cruising in an Era of Queer Liberalism. Sexualities 20 (3), pp. 364-379.

Ahmed, S. (2004). The Cultural Politics of Emotion. London: Routledge. Ahmed, S. (2010). The Promise of Happiness. Durham: Duke University Press. Albury, K. \& Byron, P. (2016). Safe on My Phone? Same-Sex Attracted Young People's Negotiations of Intimacy, Visibility, and Risk on Digital Hook-Up Apps. Social Media + Society 2 (4), pp. 1-10.

Anderson, P. L., Glidden, D. V., Liu, A., Buchbinder, S., Lama, J. R., Guanira, J. V., et al. for the iPrEx Study Team (2012). Emtricitabine-Tenofovir Concentrations and Pre-Exposure Prophylaxis Efficacy in Men Who Have Sex with Men. Science Translational Medicine 4 (151), pp.1-17. Belluz, J. (2014). The Truvada Wars. BMJ 348, pp.1-3.

Berlant, L. (2006). Cruel Optimism. Differences 17 (3), pp. 20-36.

Brown, G. (2012). Homonormativity: A Metropolitan Concept that Denigrates 'Ordinary' Gay Lives. Journal of Homosexuality 59 (7), pp.10651072.

Decoteau, C. L. (2008). The Specter of AIDS: Testimonial Activism in the Aftermath of the Epidemic. Sociological Theory 26 (3), pp. 230-257.

Derrida, J. (2006). Specters of Marx: The State of the Debt, the Work of Mourning and the New International. London: Routledge.

Douglas, M. (1966). Purity and Danger: An Analysis of Concepts of Pollution and Taboo. New York: Routledge.

Duguay, S., Burgess, J. \& Light, B. (2017). Mobile Dating and Hookup App Culture. In: P. Messaris \& L. Humphreys, eds., Digital Media: Transformations in Human Communication, New York: Peter Lang pp. 1-18. Edelman, L. (2004). No Future: Queer Theory and the Death Drive. Durham: Duke University Press.

Eisinger, R. W., Dieffenbach, C. W. \& Fauci, A. S. (2019). HIV Viral Load and Transmissibility of HIV Infection: Undetectable Equals Untransmittable. JAMA 321 (5), pp. 451-452. 
Freeman, E. (2010). Time Binds: Queer Temporalities, Queer Histories. Durham: Duke University Press.

Garcia, M. (2014). Why Michael Weinstein Gets Blamed for PrEP Myths [online]. Available at: http://www.advocate.com/31-daysprep/2014/10/31/why-michael-weinstein-gets-blamed-prep-myths. [Accessed May 3, 2019].

Gill-Peterson, J. (2013). Haunting The Queer Spaces of AIDS: Remembering ACT UP/New York and an Ethics for an Endemic. GLQ: A Journal of Lesbian and Gay Studies 19 (3), pp. 279-300.

González, O.R. (2019). Pre-Exposure Prophylaxis (PrEP), 'The Truvada Whore,' and the New Gay Sexual Revolution. In: R. Varghese, ed., Raw: PrEP, Paedagogy, and the Politics of Barebacking, Regina: University of Regina Press, pp. 47-70.

Gordon, A. F. (2008). Ghostly Matters: Haunting and the Sociological Imagination. Minnesota: University of Minnesota Press.

Kagan, D. (2015). 'Re-Crisis': Barebacking, Sex Panic and the Logic of Epidemic. Sexualities 18 (7), pp. 817-837.

Kagan, D. (2018). Positive Images: Gay Men and HIV/AIDS in the Culture of 'Post Crisis.' London: I.B. Tauris.

Møller, K. \& Petersen, M. N. (2017). Domesticating Gay Hook-Up Apps. In R. Andreassen, K. Harrison, M. Nebeling Petersen \& T. Raun, eds., Mediated Intimacies: Connectivities, Relationalities and Proximities, London: Routledge.

Mowlabocus, S. (2010). Gaydar Culture: Gay Men, Technology And Embodiment in the Digital Age. Farnham: Ashgate.

Muñoz, J. E. (2009). Cruising Utopia: The Then and There of Queer Futurity. New York: NYU Press.

Petrus, J. (2019). Discussing The Undiscussable: Reflecting on the "End" of AIDS. GLQ: A Journal of Lesbian and Gay Studies 25(1), pp. 67-72.

PrEP [online]. (2019). Available at: https://www.cdc.gov/hiv/basics/prep. html [Accessed 13 November 2019].

Race, K. (2001). The Undetectable Crisis: Changing Technologies of Risk. Sexualities 4(2), pp.167-189.

Race, K. (2015). 'Party and Play': Online Hook-Up Devices and the Emergence of PNP Practices Among Gay Men. Sexualities 18 (3), pp. 253-275. Race, K. (2018). The Gay Science: Intimate Experiments with the Problem of HIV. London: Routledge. 
Rofes, E. (1998). Dry Bones Breathe: Gay Men Creating Post-AIDS Identities And Cultures. New York: Harrington Park Press.

Scott, S. (2015). The Condomlessness of Bareback Sex: Responses to the Unrepresentability of HIV in Treasure Island Media's Plantin' Seed and Slammed. Sexualities 18 (1-2), pp. 210-223.

Snediker, M. (2008). Queer Optimism: Lyric Personhood and Other Felicitous Persuasions. Minneapolis: University of Minnesota Press.

Spieldenner, A. (2016). PrEP Whores and HIV Prevention: The Queer Communication of HIV Pre-Exposure Prophylaxis (PrEP). Journal of Homosexuality 63 (12), pp. 1685-1697.

Treatment as Prevention (TASP) for HIV [online]. (2019). Available at: https://www.avert.org/professionals/hiv-programming/prevention/ treatment-as-prevention [Accessed 13 November 2019].

Treichler, P. A. (1999). How to Have Theory in an Epidemic: Cultural Chronicles of AIDS. Durham: Duke University Press. 